\title{
Survey of Radioactive Items in the Home
}

\author{
Elizabeth E. Kritzberger, CNMT, NMTCB(CT), and Liliana Navarrete \\ Clinical and Diagnostic Sciences Department, University of Alabama at Birmingham, Birmingham, Alabama
}

CE credit: For CE credit, you can access the test for this article, as well as additional JNMT CE tests, online at https://www.snmmilearningcenter.org. Complete the test online no later than December 2020. Your online test will be scored immediately. You may make 3 attempts to pass the test and must answer $80 \%$ of the questions correctly to receive $1.0 \mathrm{CEH}$ (Continuing Education Hour) credit. SNMMI members will have their CEH credit added to their VOICE transcript automatically; nonmembers will be able to print out a CE certificate upon successfully completing the test. The online test is free to SNMMI members; nonmembers must pay $\$ 15.00$ by credit card when logging onto the website to take the test.

Whether it be from the sun or naturally encountered substances, we are exposed to radiation every day. Some items found in the home either are naturally radioactive or have a component containing radioactive material. This study was conducted to assess exposure from 4 such items previously shown to be radioactive: Fiestaware, granite, smoke detectors, and Brazil nuts. Using 3 types of radiation detectors to obtain quantitative and qualitative information on the radioactive properties of these items, we found little to no harmful radiation exposure from any of them.

Key Words: radiation exposure; granite; Fiestaware; smoke detectors; Brazil nuts

J Nucl Med Technol 2017; 45:253-258

DOI: $10.2967 /$ jnmt.117.196451

$\mathbf{W}$

hether it be from the sun or naturally encountered substances, we are exposed to radiation every day. Some items found in the home either are naturally radioactive or have a component containing radioactive material. This study was conducted to assess exposure from 4 such items previously shown to be radioactive: Fiestaware (Homer Laughlin China Co.), granite, smoke detectors, and Brazil nuts. We chose these items to study because they are known to have radioactive properties and there is previous research regarding their radioactivity.

A study in 2002 found radioactivity in older ceramicware (1). According to an article by Oak Ridge Associated Universities (2), some ceramicware gets its color from a glaze applied during production. An example of such ceramicware is the Fiestaware produced in West Virginia between 1936 and 1973. Of the 5 original colors of Fiestaware, the red and ivory colors were slightly radioactive because of

\footnotetext{
Received Jun. 1, 2017; revision accepted Oct. 4, 2017.

For correspondence or reprints contact: Liliana Navarrete, University of Alabama at Birmingham, 1716 Ninth Ave. South, SHPB 450, Birmingham, AL 35294.

E-mail: lilinav@uab.edu

Published online Oct. 17, 2017.

COPYRIGHT (C) 2017 by the Society of Nuclear Medicine and Molecular Imaging.
}

the materials used to make the glaze. Red Fiestaware, or Fiesta Ironstone as it was later known, was the most expensive because it was made using natural uranium between 1936 and 1943 and then depleted uranium between 1959 and 1973. Our goal with the Fiestaware was not only to see if we could find a radioactive piece available to the public but also to see if the radioactive items would leach radioactivity when left in contact with acidic substances.

It has been known for some time that some granite has naturally radioactive properties, as studied by the Atomic Energy Commission and other entities in 1955 (3). Known radioisotopes found in granite include uranium and thorium; however, these two make up very small portions of granite $(4,5)$. Radon gas $\left({ }^{222} \mathrm{Rn}\right)$ also is known to be a natural constituent of natural stones, such as granite, used as building materials ( 6 ). Granite is a beautiful addition to any home and is still the most popular kitchen countertop. Our goal was to measure a few samples obtained from a local granite distributor to see if there would be any variation from one sample to another and whether radiation from the granite would pose a threat to a homeowner's health.

There has been little research on the radioactivity of smoke detectors. A fact sheet provided by the Health Physics Society suggests a small amount of a radioactive metal known as ${ }^{241} \mathrm{Am}$ is present in some residential smoke detectors (7). ${ }^{241} \mathrm{Am}$ is optimum for use in smoke detectors because it is an $\alpha$-emitter and has a long half-life, 470 y ( 8 ). Half-life refers to the amount of time it takes for half of a radioactive material to decay; therefore, it would take $470 \mathrm{y}$ for half of a ${ }^{241} \mathrm{Am}$ source to decay. Knowing this, we wanted to see if there was any possible harm to homeowners who have smoke detectors that contain a radioactive material with such a long half-life.

Several studies have been conducted to ascertain the radioactivity of Brazil nuts and whether any activity found is absorbed by the body (9). Brazil nuts are not a staple in the American diet, but they can be found in some supermarkets. A study published by Turner et al. surveyed several foods, including Brazil nuts, bananas, cereal, and tea. The study showed that of all the food items measured, Brazil nuts were the most active (9). According to Penna-Franca et al., 
the Brazil nut tree has an extensive root system with an unusual affinity to absorb and concentrate barium (10). In the process of absorbing nutrients from the soil, it also absorbs and concentrates ${ }^{226} \mathrm{Ra}$ and ${ }^{228} \mathrm{Ra}$. This happens because radium and barium have similar chemical behavior (10). Our goal was to see if raw Brazil nuts purchased from a local supermarket would give us any readings above background level.

We also investigated how these items compare with the background radiation we receive from the sun, our surroundings, and medical procedures such as CT scans. Natural radiation background includes radon and thoron gases as well as cosmic and internal radiation. Manmade radiation sources include medical scans, such as CT scans, and other medical procedures, as well as consumer products - tobacco, fertilizers, and many more (11). Exposure rate is the amount of radiation we are exposed to over a certain amount of time. According to the U.S. Nuclear Regulatory Commission, radiation may not be harmful in small doses such as a chest x-ray or a limited CT scan, especially when there is a period between exposures, as this period allows our cells to regenerate, or to die and be replaced by new, healthy cells. However, the Nuclear Regulatory Commission requires its licensees to limit exposure to the public to $100 \mathrm{mrem} / \mathrm{y}$ above background level (11).

\section{MATERIALS AND METHODS}

Three instruments were used to measure the presence of radioactivity. A Geiger-Mueller counter (model 2401-P; Ludlum) (GM) was used to assess the possible radioactivity of each item and to see if one area of an item was more radioactive than another. It is the preferred instrument when surveying an area for radiation. If we found that an item was radioactive, we measured it again using a handheld radioactive isotope identifier (SAM-940; Berkley Nucleonics) to determine what element was present. If the other instruments were not able to detect anything, a well counter (Unispec; Canberra) was used to see if any significant results could be measured. The well counter works similarly to the SAM940 , but it is not handheld because the instrument and sample are surrounded by thick lead shielding to block most background radiation and ensure a more sensitive reading (Fig. 1).

FIGURE 1. Canberra Unispec well counter with lead protection.
TABLE 1

Average Yearly Exposure to Radiation According to Nuclear Regulatory Commission (11)

\begin{tabular}{lr}
\hline \multicolumn{1}{c}{ Source } & Exposure \\
\hline Natural background & $310 \mathrm{mrem}$ \\
Manmade sources & $310 \mathrm{mrem}$ \\
Head scan $(\mathrm{CT})^{\star}$ & $200 \mathrm{mrem}$ \\
Chest x-ray* & $10 \mathrm{mrem}$ \\
Dental x-ray & $1.5 \mathrm{mrem}$ \\
\hline & \\
\hline *Single exposure. & \\
Public limit $=100 \mathrm{mrem} / \mathrm{y}$. & \\
\hline
\end{tabular}

First, the background level of radiation was measured for 5 min using the GM counter. Each item was then placed directly in contact with the GM detector and measured for $5 \mathrm{~min}$, after which the counts and exposure rate were recorded. These readings were then compared with the average annual exposure to radiation from the natural background, manmade sources, head CT scans, chest x-rays, and dental x-rays, as published by the Nuclear Regulatory Commission (Table 1).

Regarding the ceramicware, we hypothesized that the acidity of some foods would leach radioactivity from the items. We chose to use orange juice and lime juice for testing because they are acidic and would allow us to simulate leaching of radiation by foods in common use as would occur in everyday life. In the orange juice testing, an unmeasured volume of juice was poured into each item, which was then covered and refrigerated for approximately $20 \mathrm{~h}$. In the lime juice testing, a 40-mL volume of juice was poured into each item, which was then covered and refrigerated for approximately $96 \mathrm{~h}$. Afterward, the juice was pipetted into plastic test tubes (orange juice) or small beakers (lime juice), with cotton swabs being used to collect the remainder. The background level of radiation was measured for 5 min using the well counter, and the juice and swabs were then measured for the same amount of time.

\section{RESULTS}

\section{Fiestaware}

We tested 6 items of colored Fiestaware or similarly made ceramicware we believed could be radioactive (Fig. 2). Only items 1 (small orange saucer), 2 (small yellow saucer), 3 (bright orange bowl), and 6 (large yellow plate) were marked as Fiestaware brand. Item 4 (large orange plate) had no markings, and we were unsure whether it was Fiestaware. Items 1 and 2 were purchased sometime in the 1970s. Items 3 and 4 were made circa the 1950s and kept in our lab because they were known to be radioactive and were used for demonstration purposes. Items 5 (ivory gravy boat) and 6 were bought from an antique shop in the summer of 2015. Item 5 was made by the Homer Laughlin China Co. but was not branded as Fiestaware. However, Fiestaware was not the only line of ceramicware the Homer Laughlin China Co. produced.

The GM counter found that items 3, 4, and 5 had counts significantly above the background level (Table 2). The values were consistent with previous reports of up to 32 $\mathrm{mrem} / \mathrm{h}$ at the surface of ceramic tableware $(2,12)$.

The SAM-940 identified ${ }^{238} \mathrm{U}$ in all 3 items with at least $96 \%$ certainty, indicating the use of uranium in the production 


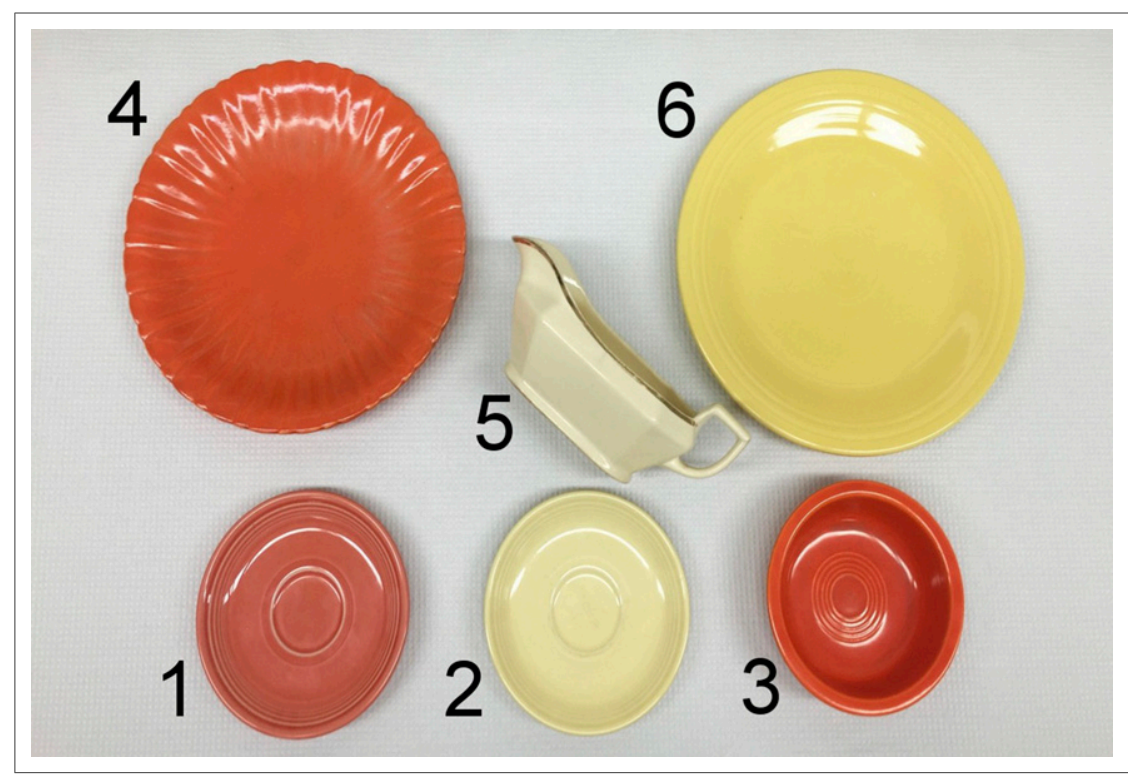

FIGURE 2. Glazed ceramicware: items 1-6. also, by being set to collect counts for $5 \mathrm{~min}$, allowed us to see whether there was any difference from background counts. Thus, we measured with the SAM-940 only those areas predetermined by the GM counter to be radioactive. We did not take measurements farther from the sample's surface because the readings with the GM counter at the surface were equal to the background level. Readings were taken on both the polished side and the unpolished side of each sample, with the latter being somewhat higher (Table 3).

Neither side of sample 4 showed any readings above the background level.

Sample 1 showed readings above background level on both sides.

The SAM-940 was at least $72 \%$ certain that ${ }^{232} \mathrm{Th}$ was present in samples 1, 2, and 3. Readings showed the darker spots to be ${ }^{232} \mathrm{Th}$. of the ivory and bright orange glazes. In addition, ${ }^{241} \mathrm{Am}$ was found in item 4 with $73 \%$ certainty.

The 3 items that were found to be radioactive (items 3, 4, and 5) were used in the juice testing. In the orange juice testing, no significant reading above background level was detected. In the lemon juice testing, no significant reading above background level was detected for items 3 or 5 . For item 4 , most of the juice had evaporated, leaving a film of citrate. The citrate was collected using cotton swabs, which were then placed in a test tube and measured in the well counter, showing a reading of about 1.4 times background level.

\section{Granite}

We tested 4 samples of granite from a local distributor (Fig. 3).

Samples 2 and 3 seemed to be from the same type of granite, but we measured them separately. We used the GM counter to determine possible areas of radiation, focusing on areas with a higher concentration of dark spots because those areas produced sporadic spikes in our GM counter. Unfortunately, those spikes did not last long enough to produce an exposure rate above the background level. However, we found that the SAM-940 not only allowed us to identify the radioisotope but

\section{Smoke Detectors}

We tested 2 smoke detectors, the first of which was an older detector used in our lab for demonstration purposes. The cover was removed for the recording of measurements (Fig. 4). We could clearly see the warning "Caution Radioactive Material" over a small metal housing indicating where the radioactive source was contained, but we used the GM counter to confirm this location and then used the SAM-940 to identify the radioisotope, which it confirmed with $74 \%$ certainty to be ${ }^{241} \mathrm{Am}$. Then, we measured exposure at the surface; at a $0^{\circ}$ angle $30 \mathrm{~cm}$ (12 in) and $61 \mathrm{~cm}$ (24 in) from the surface; and, to see if there was any preferential direction, at $30^{\circ}$ and $60^{\circ}$ angles $61 \mathrm{~cm}$ (24 in) from the surface. The extra measurements were done to simulate real-life exposure of a bed positioned under a smoke detector. Only measurements at the surface had a reading above ( $\sim 7$ times) the background level. No measurement at any other distance or angle had a reading above the background level.

The second smoke detector was recently manufactured. Because the cover of this detector could not be easily removed, we measured several areas of the cover with the GM counter to find the radioactive source. Once the probable location of the source was determined, we obtained measurements

TABLE 2

GM Readings at Surface of Fiestaware Samples

\begin{tabular}{cccccc}
\hline Item 1 & Item 2 & Item 3 & Item 4 & Item 5 & Item 6 \\
\hline Background & Background & $6.65 \mathrm{mR} / \mathrm{h}$ & $8.50 \mathrm{mR} / \mathrm{h}$ & $0.10 \mathrm{mR} / \mathrm{h}$ & Background \\
& & & & \\
\hline Background $=0.01 \mathrm{mR} / \mathrm{h}$. & & & \\
\hline
\end{tabular}




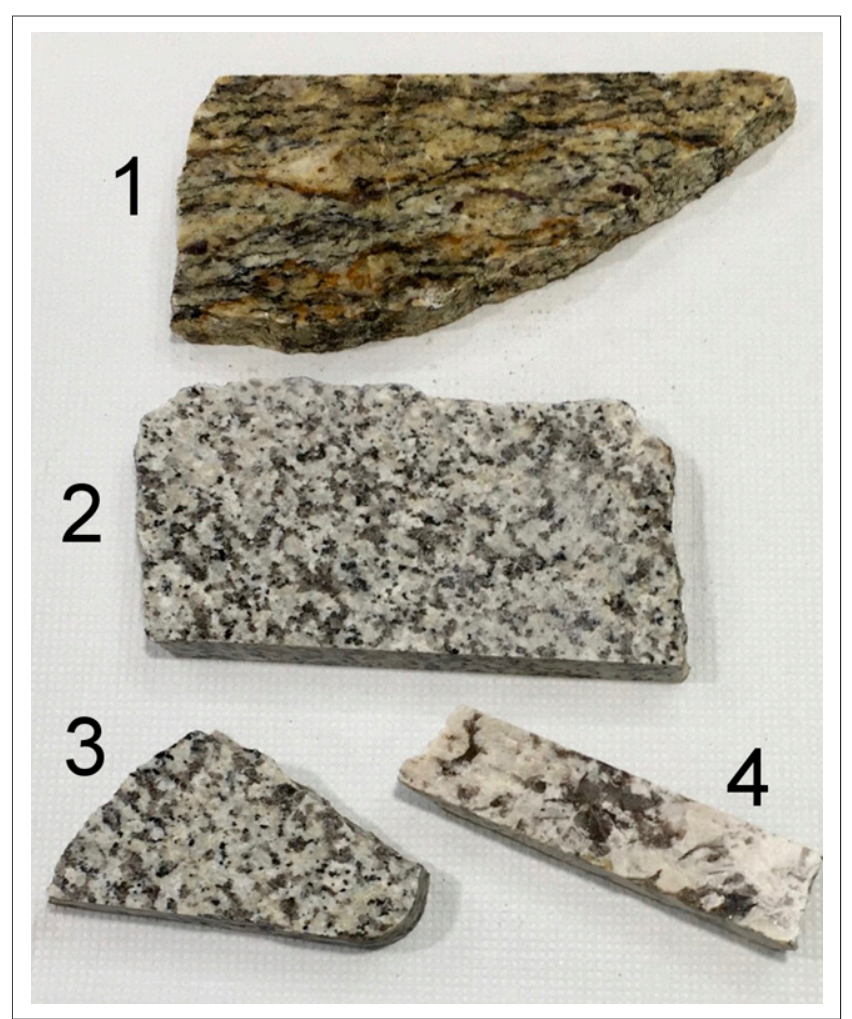

FIGURE 3. Granite: samples 1-4.

at the same distances and angles as for the first smoke detector. At the surface, the SAM-940 was at least $73 \%$ certain ${ }^{241} \mathrm{Am}$ was present. Only measurements at the surface had a reading above ( $\sim 3$ times) the background level.

\section{Brazil Nuts}

The GM counter and SAM-940 showed no significant results above the background level when placed in contact with $454 \mathrm{~g}$ (1 lb) of raw Brazil nuts purchased from a local supermarket. In addition, the SAM-940 could not identify any radioisotopes with 5-min readings. When we did not get a significant reading with the GM or SAM-940, we tried the well counter. Previous studies (10) used ash of Brazil nuts to determine their possible radioactivity, but we used whole and crushed Brazil nuts. We crushed one raw nut and placed it in a test tube to be read, and the results were indistinguishable from the background level. We then placed the entire 454-g (1-lb) bag of Brazil nuts into the well counter, and the reading was consistently about 1.3 times the background level.

\section{DISCUSSION}

\section{Fiestaware}

Of the 3 Fiestaware items found to be radioactive by using the GM counter, item 4 had the most significant reading above the background level. This item also leached radioactivity into acidic juices left in contact with it. We believe these findings may be because the plate was scratched and the clear glaze meant to protect it had worn away from a shiny to a matte appearance. Since we measured the items only at the surface, we cannot assess exposure when they are used as display pieces in homes or public facilities. However, an individual handling our item 4 would receive up to $8.5 \mathrm{mR} / \mathrm{h}$ to the palms and fingers. NUREG-1717 estimates that an individual would receive about $7 \mathrm{mrem} / \mathrm{y}$ only from handling this type of ceramic tableware. They also estimate that an individual eating from primarily this type of dinnerware would receive up to 40 $\mathrm{mrem} / \mathrm{y}$ by ingesting foods containing uranium leached from the glazes. This is for acidlike food-derived liquids in contact with the ceramicware for $24 \mathrm{~h}$ or more (12).

None of the newer Fiestaware was found to be radioactive. Item 5, with an ivory glaze, which we found in a local antique store in 2015 did not leach any radioactivity when exposed to acidic juice, even though its shiny glaze was also wearing away. However, it is concerning that antique stores, aware or unaware, can sell radioactive items. There are also online companies claiming to sell original vintage Fiestaware circa the 1940s. They are probably aware that glazes may contain uranium oxide, but the word radioactive is never mentioned on their websites. Since most radioactive antiques were made before the health risks of radioactive materials were known, and even today no regulation exists, our concern is about the public being able to easily buy such items in poor condition and use them to store foods. In our item 4 , we found both ${ }^{238} \mathrm{U}$ and ${ }^{241} \mathrm{Am}$, which emit $\alpha$-radiation. $\alpha$-radiation does not travel much more than a few inches in air and cannot penetrate skin; therefore, it is not harmful externally, but it is very harmful if ingested in a soluble form. This is our clearest example of the type of harm that one cannot see, smell, feel, or taste but is there nonetheless and can pose harm to those not aware of its existence. Because we cannot sense the radiation, it is probably best, when cooking or serving food, not to use older ceramicware that is the same color as those that were manufactured using a radioactive glaze.

TABLE 3

SAM-940 Detector Readings at Surface of Polished and Unpolished Sides of Granite Samples

\begin{tabular}{|c|c|c|c|c|c|c|c|}
\hline \multicolumn{2}{|c|}{ Sample 1} & \multicolumn{2}{|c|}{$\begin{array}{c}\text { Sample } 2 \\
\end{array}$} & \multicolumn{2}{|c|}{ Sample 3} & \multicolumn{2}{|c|}{ Sample 4} \\
\hline Polished & Unpolished & Polished & Unpolished & Polished & Unpolished & Polished & Unpolished \\
\hline $228.5 \mathrm{cps}$ & $228.9 \mathrm{cps}$ & $284.7 \mathrm{cps}$ & $287.9 \mathrm{cps}$ & Background & $246.3 \mathrm{cps}$ & Background & Background \\
\hline
\end{tabular}

Five-minute background $=172.5 \mathrm{cps}$. 


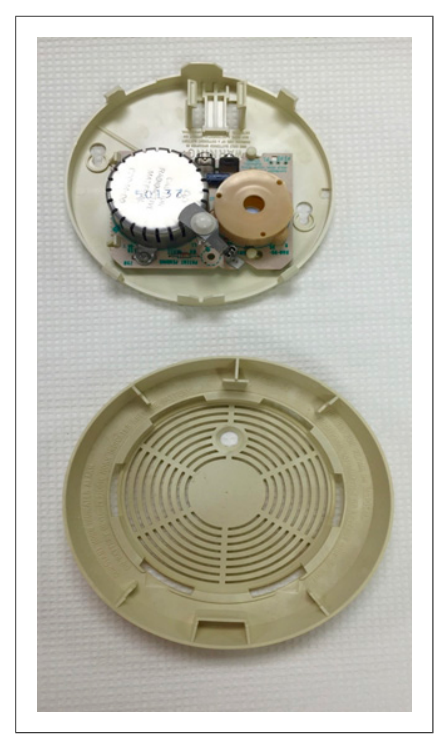

FIGURE 4. Older smoke detector with cover removed.

\section{Granite}

We have shown a variability of radiation emissions from different types of granite. The higher readings on the unpolished side may be due to a thin barrier created during the polishing, sealing, and buffing processes.

Spiking of the GM counter at higher concentrations of dark spots can be attributed to the presence of thorium. In addition, thorium is known to tarnish to a dark gray or black color when exposed to air for an extended period (4). These results are at the surface of the granite; exposure decreases farther from the surface, and not all granite has radioactive properties. ${ }^{232} \mathrm{Th}$ is an $\alpha$-emitter, and $\alpha$-radiation can be stopped by a thin layer of material with a low atomic number such as any chemical used in the sealing process of the granite. Myatt et al., after measuring 27 different varieties of granite, estimated the effective dose received from countertop-related radiation emissions to be between 3 and $18 \mathrm{mrem} / \mathrm{y}$ (5). Their measurements were collected at predetermined and evenly spaced sampling locations on the polished side of full-size slabs. Their modeled dose rate is based on a person spending $4 \mathrm{~h} / \mathrm{d}$ in the kitchen, either in contact with or within $15 \mathrm{~cm}$ of the polished side of the counter. They did not measure or consider the unpolished side of a countertop, mainly because there is usually no exposure to that side.

They also did not consider that granite is sometimes used as dining and desk tabletops as well. In addition, granite in a kitchen island extension is sometimes used as a dining table, and granite in kitchen counters is sometimes used as a home office desk. In such cases, the time that the chest and upper limbs spends in close contact with granite increases dramatically, compared with the study mentioned above. We must also consider that a person in a sitting position is exposed to both the polished and the unpolished sides of the granite slab. We have shown the unpolished side to have higher readings. In the sitting position, the lower limbs and lower body are also exposed. To our knowledge, none of this has been taken into consideration in the literature so far.

Myatt et al. found one type of exotic granite with areas of activity having maximum counts above $118,000 \mathrm{cpm}$ (5). This represents an annual dose of about $7.1 \mathrm{mrem} / \mathrm{y}$ based on an exposure of $1 \mathrm{~h} / \mathrm{d}$ for $365 \mathrm{~d}$ (5). Use of that type of granite as more than a kitchen countertop, for only $4 \mathrm{~h}$ a day, well exceeds $25 \%$ of an individual's annual effective dose of $100 \mathrm{mrem} / \mathrm{y}$ from a single manmade source. Even though the highest reading from the items we measured would add an exposure of about $10 \mathrm{mrem} / \mathrm{y}$ if in daily close contact for $4 \mathrm{~h}$, it is imperative to do a serious assessment of granite. The unpolished side of exotic types of granite is of particular concern, since they are becoming more popular and now have more uses than just as a kitchen countertop.

\section{Smoke Detectors}

Smoke detectors are not much of a hazard because they are usually placed on ceilings, and we found radiation levels above the background level only at the surface of the radioactive source. Therefore, from our measurements, a person standing or sleeping more than $30 \mathrm{~cm}$ (12 in) from a smoke detector would be receiving an amount of radiation exposure indistinguishable from normal background radiation. NUREG-1717 estimates an exposure of $0.001 \mathrm{mrem} / \mathrm{y}$ for a person sleeping $8 \mathrm{~h}$ a day in a room with a smoke detector (12).

The significant difference in surface readings between the older and newer detectors could have been because the cover was attached to the newer one. The radioactive source used in the surveyed detectors, ${ }^{241} \mathrm{Am}$, is a known $\alpha$-emitter. $\alpha$-particles in ${ }^{241} \mathrm{Am}$ do not travel more than a few inches in air and are easily stopped by material such as plastic covers.

\section{Brazil Nuts}

The level of radiation we found using the well counter, about 1.3 times the background level, means if someone were to eat a pound of Brazil nuts a year, that person would receive only a small amount of radiation. An individual who loves Brazil nuts and eats a pound a week would receive an additional exposure of about $26 \mathrm{mrem} / \mathrm{y}$, or the equivalent of about 2 chest x-rays a year (Table 1). However, Brazil nuts are not a staple in most diets. If ingestion of radium is the concern, studies have shown that the body does not absorb ${ }^{226} \mathrm{Ra}$ from Brazil nuts (2).

\section{CONCLUSION}

Using 3 types of radiation detectors to obtain quantitative and qualitative information on the radioactive properties of Fiestaware, granite, smoke detectors, and Brazil nuts, we found little to no harmful radiation exposure from any of them. 


\section{DISCLOSURE}

No potential conflict of interest relevant to this article was reported.

\section{ACKNOWLEDGMENTS}

We thank the University of Alabama at Birmingham Nuclear Medicine Technology program for facilitating the use of all instruments and lab space to conduct this study.

\section{REFERENCES}

1. Norman EB. On the radioactivity of Fiestaware. eScholarship website. http:// escholarship.org/uc/item/5mb3p5fw. Published March 13, 2002. Accessed October 16, 2017.

2. Radioactive consumer products. Oak Ridge Associated Universities website. http://www.orau.org/ptp/collection/consumer\%20products/consumer.htm. Published 1999. Accessed October 16, 2017.

3. Brown H, Silver LT. The possibilities of obtaining long-range supplies of uranium, thorium, and other substances from igneous rocks. CaltechAUTHORS website. http://resolver.caltech.edu/CaltechAUTHORS:20151021-094312456. Published 1956. Accessed October 16, 2017.
4. Thorium - Th. Lenntech website. http://www.lenntech.com/periodic/elements/th. htm. Accessed October 16, 2017.

5. Myatt TA, Allen JG, Minegishi T, et al. Assessing exposure to granite countertopspart 1: radiation. J Expo Sci Environ Epidemiol. 2010;20:273-280.

6. Allen JG, Minegishi T, Myatt TA, Stewart JH, McCarthy JF, MacIntosh DL. Assessing exposure to granite countertops-part 2: radon. J Expo Sci Environ Epidemiol. 2010;20:263-272.

7. Consumer Products Containing Radioactive Materials. Health Physics Society website. https://hps.org/documents/consumerproducts.pdf. Adopted: February 2010. Accessed October 16, 2017.

8. Radioisotopes in consumer products. World Nuclear Association website. http:// www.world-nuclear.org/information-library/non-power-nuclear-applications/ radioisotopes-research/radioisotopes-in-consumer-products.aspx. Updated June 2017. Accessed October 27, 2017.

9. Turner RC, Radley JM, Mayneord WV. The naturally occurring alpha-ray activity of foods. Health Phys. 1958;1:268-275.

10. Penna-Franca E, Fiszman M, Lobao N, et al. Radioactivity of brazil nuts. Health Phys. 1968;14:95-99.

11. Backgrounder on Biological Effects of Radiation. United States Nuclear Regulatory Comission website. https://www.nrc.gov/reading-rm/doc-collections/factsheets/bio-effects-radiation.html. Published March 2017. Updated May 22, 2017. Accessed October 16, 2017.

12. Systematic Radiological Assessment of Exemptions for Source and Byproduct Materials: NUREG 1717. Washington, DC: Nuclear Regulatory Commission; 2001. 